Longitudinal Experience-Wide Association Studies (LEWAS) - A Framework for Studying Personality Change

Wiebke Bleidorn and Christopher J. Hopwood, University of California, Davis, United States Mitja D. Back, University of Münster, Germany

Jaap J. A. Denissen, Tilburg University, The Netherlands

Marie Hennecke, University of Siegen, Germany

Markus Jokela, University of Helsinki, Finland

Christian Kandler, University of Bremen, Germany

Richard E. Lucas, Michigan State University, United States

Maike Luhmann, Ruhr University Bochum, Germany

Ulrich Orth, University of Bern, Switzerland

Brent W. Roberts, University of Illinois, United States

Jenny Wagner, University of Hamburg, Germany

Cornelia Wrzus, University of Heidelberg, Germany

Johannes Zimmermann, University of Kassel, Germany

In press: European Journal of Personality

Correspondence concerning this article should be addressed to Wiebke Bleidorn, Department of Psychology, University of California Davis, One Shields Avenue, Davis, CA 95616, United

States. E-mail: wiebkebleidorn@gmail.com The authors are members of the Personality Change Consortium (PCC).

Running head: PERSONALITY CHANGE 


\begin{abstract}
The importance of personality for predicting life outcomes in the domains of love, work, and health is well established, as is evidence that personality traits, while relatively stable, can change. However, little is known about the sources and processes that drive changes in personality traits, and how such changes might impact important life outcomes. In this paper, we make the case that the research paradigms and methodological approaches commonly used in personality psychology need to be revised to advance our understanding of the sources and processes of personality change. We propose Longitudinal Experience-Wide Association Studies (LEWAS) as a framework for studying personality change that can address the limitations of current methods, and discuss strategies for overcoming some of the challenges associated with LEWAS.
\end{abstract}

Keywords: personality development, Big Five, longitudinal designs, traits, states 
Once a niche topic, personality development has become one of the most widely studied phenomena in personality science. There is now convincing evidence that personality traits continue to change throughout the lifespan (Bleidorn \& Hopwood, 2019; Roberts, Walton, \& Viechtbauer, 2006; Orth, Robins, \& Widaman, 2010; Specht et al., 2014), sometimes in response to environmental influences (Bleidorn, Hopwood, \& Lucas, 2018), including purposeful interventions (Roberts, Luo, Chow, Su, \& Hill, 2017). These findings would appear to provide a solid foundation for a deeper understanding of the sources and processes that drive personality change. However, surprisingly little is known about when, why, and how personality traits change. Although many studies have linked life experiences to personality traits in an attempt to understand why personality changes, these efforts have been hampered by conceptual, methodological, and data limitations.

In this paper, we make the case that a thorough understanding of the sources and processes of personality change requires a major revision of current theoretical models and practices in research on personality change. In particular, we envision a paradigmatic shift in personality research towards Longitudinal Experience-Wide Association Studies (LEWAS) designed to derive maps of experiences, behaviors and life paths that are associated with changes in personality traits. In what follows, we lay out the rationale for this paradigm shift, derive characteristics of LEWAS, and discuss open questions and issues for future research.

Throughout, we refer to traits as relatively enduring patterns of thoughts, feelings, strivings, and behaviors that distinguish individuals from each other (Allport, 1961). The material manifestation of traits can be found in personality states, which refer to specific thoughts, feelings, motives, and behaviors exhibited in any given moment (Fleeson, 2001). We organize our review and discussion in reference to the Big Five taxonomy: openness to 
experience, conscientiousness, extraversion, agreeableness, and neuroticism/emotional stability (John \& Srivastava, 1999). However, we acknowledge the value of narrower and broader traits beyond the Big Five (Ashton \& Lee, 2007; Mõttus, Kandler, Bleidorn, Riemann, \& McCrae, 2017; Orth \& Robins, 2014), most of which can be organized within a broad and inclusive hierarchical framework (Markon, Krueger, \& Watson, 2005) and also recognize the potential importance of other personality constructs (DeYoung, 2015; McCrae \& Costa, 2008; McAdams \& Olson, 2010).

\section{Personality Stability and Change}

One reason for the long-lasting debates over whether personality traits are stable or changeable rests on the fact that researchers have failed to clarify what they mean when they use such terms. Three indices have emerged as particularly relevant: rank-order consistency, meanlevel change, and individual differences in change (De Fruyt et al., 2006; Morey \& Hopwood, 2013; Roberts, Wood, \& Caspi, 2008).

Rank-order consistency - often expressed as test-retest correlation - indicates the degree to which different people experience more or less change relative to one another. Meta-analytic evidence (Roberts \& DelVecchio, 2000) provides robust evidence that individual differences in personality traits are quite - but not completely - consistent over time. Comparable to many other social science variables, such as income, life satisfaction, or self-esteem (Fujita \& Diener, 2005; Orth \& Robins, 2014), retest correlations of personality traits typically range between .40 to .60 over 10 -year time lags. Moreover, personality traits appear to increase in rank-order stability throughout the lifespan, peaking between the ages of 50 and 60 , with a plateau or decrease after that decade (Kandler et al., 2010; Lucas \& Donnellan, 2011; Terracciano, Costa, 
$\&$ McCrae, 2006). This pattern suggests that personality traits are most prone to change in early and late adulthood.

Mean-level change - often expressed as standardized mean-level differences across time or age groups - reflects the degree to which a trait decreases or increases among all people in a population, on average. Meta-analyses and large-scale, population-based studies show that personality traits change throughout the lifespan and that these changes can be quite substantial (Orth, Erol, \& Luciano, 2018; Roberts et al., 2006; Lucas \& Donnellan, 2011), particularly during young adulthood. Specifically, most young adults tend to increase in trait levels that are considered socially desirable such as emotional stability, conscientiousness, and agreeableness (Bleidorn, 2015). This normative pattern of personality maturation appears to generalize across cohorts, genders, and, to a certain degree also across samples from different cultures (Bleidorn et al., 2013; Roberts et al., 2006; Wortman, Lucas, \& Donnellan, 2012). Although mean-level changes in middle adulthood are somewhat less pronounced, the majority of studies that have examined older age groups support the argument that personality traits continue to change throughout the lifespan (Kandler, Kornadt, Hagemeyer, \& Neyer, 2015; Mõttus, Johnson, \& Deary, 2012; Mueller et al., 2016; Wagner, Ram, Smith, \& Gerstorf, 2016). Indeed, some studies suggest that the personality maturation trends that characterize young and middle adulthood are reversed in late adulthood, in that some of the most pronounced mean-level changes in emotional stability, agreeableness, extraversion, and conscientiousness occur during very old age ( $>80$ years; cf. Mõttus et al. 2012; Wortman et al., 2012).

Individual differences in change - often expressed as variance or standard deviation - ask how closely individuals conform to vs. deviate from the overall mean-level trends. Although this type of change has been studied less often than rank-order stability or mean-level change, there is 
an emerging body of evidence for individual differences in personality change throughout the lifespan (Schwaba \& Bleidorn, 2018). For instance, although most people tend to increase in agreeableness as they navigate young adulthood, some people remain stable or even decrease in this trait (e.g., Jackson, Thoemmes, Jonkmann, Lüdtke, \& Trautwein, 2012; Lüdtke, Roberts, Trautwein, \& Nagy, 2011). Again, individual differences in personality change appear to be most pronounced during young adulthood (Schwaba \& Bleidorn, 2018) providing further evidence that young adulthood may be a critical period for personality change.

In summary, questions about personality trait stability and change are conditioned on the metric being used to quantify those concepts. In general, rank-order, mean-level, and individual differences in change all need to be considered in order to understand both population trends and individual trajectories. Taken together, existing research suggests that a) personality traits are relatively rank-order stable, b) people tend to change in the direction of greater maturity, c) people change in different ways, and d) young adulthood might be a particularly important time for personality change and maturation. A central premise of the PCC and this paper is that the next generation of personality research should build upon these descriptive findings to focus on how, why, and when changes occur, and how personality change can be leveraged for public good (Bleidorn, Hill, et al., in press). In the next section, we summarize evidence for the importance of personality change for individual and societal well-being.

\section{Why Should We Care About Personality Change?}

A large body of evidence documents the power of personality traits to predict outcomes in all major life domains (Bleidorn, Hill et al., in press; Ozer \& Benet-Martinez, 2006; Roberts, Kuncel, Shiner, Caspi, \& Goldberg, 2007; Soto, in press). In the domain of health, for instance, conscientiousness predicts preventative health behaviors and a lower frequency of risky health 
behaviors (Bogg \& Roberts, 2004), general physical health (Hampson, Goldberg, Vogt, \& Dubanoski, 2007; Moffitt et al., 2011), a lower risk for Alzheimer's Disease (Wilson, Boyle, Yu, Segawa, Sytsma, \& Bennett, 2015), and longevity (Kern \& Friedman, 2008). These effects are similar in magnitude to those of factors widely accepted as important health determinants, such as socioeconomic status and cognitive ability (Roberts et al., 2007).

It has also become widely accepted that personality traits are key to understanding and predicting mental health problems (Hopwood, Thomas, Markon, Wright, \& Krueger, 2012; Kendler \& Myers, 2010; Kotov, Gamez, Schmidt, Watson, 2010). High levels of neuroticism, in particular, are at the core of virtually all major psychiatric diagnoses (Malouff, Thorsteinsson, \& Schutte, 2005; Ormel et al., 2013; Samuel \& Widiger, 2008). Low levels of conscientiousness and agreeableness have been also linked to a range of externalizing problems, including conduct disorders (Miller \& Lynam, 2001), substance abuse (Sher \& Trull, 1994; Walton \& Roberts, 2004); and antisocial behavior more generally (Atherton, Zheng, Bleidorn, \& Robins, in press; Krueger, Hicks, Patrick, Carlson, Iacono, \& McGue, 2002).

Personality traits also play a major role in predicting people's educational, occupational, and interpersonal outcomes. For example, conscientiousness and openness predict academic achievement in both high school and college contexts, independent of cognitive ability (Israel, Lüdtke, \& Wagner, 2019; Noftle \& Robins, 2007; Spengler, Brunner, Martin, \& Lüdtke, 2016). Traits are reliable predictors of work outcomes, including occupational choice (Denissen, Ulferts, Lüdtke, Muck, \& Gerstorf, 2014); job performance (Dudley, Orvis, Lebiecki, \& Cortina, 2006), leadership (Judge, Bono, Ilies, Gerhardt, 2002), income (Denissen et al., 2019), and occupational attainment (Roberts et al., 2007). There is also a large body of evidence highlighting the role of personality traits in predicting romantic relationship outcomes and 
marital trajectories (Asendorpf, Penke, \& Back, 2011; Luciano \& Orth, 2017; Neyer \& Lehnart, 2008; Malouff, Thorsteinsson, Schutte, Bhullar, \& Rooke, 2010; Roberts et al., 2007, Wagner et al., 2015), friendship, popularity, and status in peer relations (Anderson, John, Keltner, \& Kring, 2011; Back, Schmukle, \& Egloff, 2011; Selfhout, Burk, Denissen, Branje, van Aken, \& Meeus, 2010; Stopfer, Egloff, Nestler, \& Back, 2013) as well as subjective well-being and overall functioning (Bleidorn et al., in press; Lucas \& Diener, 2015; Mueller, Wagner, Wagner, Ram, \& Gerstorf, in press).

Overall, evidence that personality traits are associated with important life outcomes is robust and convincing. However, all of the aforementioned studies have focused on how personality traits assessed at one point in time are associated, concurrently or prospectively, with consequential outcomes. This emphasis on stable traits as static predictors might contribute to the perception that dispositional traits are useful for predicting long-term outcomes but of little relevance for interventions intended to change personality traits. But this would belie researchers' more recent interest in the implications of personality trait change for changes in relevant life outcomes.

For example, increases in conscientiousness have been associated with improvements in ratings of physical health and endorsement of positive health behaviors (Takahashi, Edmonds, Jackson, \& Roberts, 2013). Similarly, increasing levels of neuroticism and decreasing levels of conscientiousness have been associated with increases in stress, negative life events, and mental health problems (Luo, Derringer, Briley, \& Roberts, 2017; Ormel et al., 2013), whereas increasing levels of conscientiousness and decreasing levels of neuroticism predicted improved physical (Chow \& Roberts, 2014; Lee, Ellingson, \& Sher, 2015; Roberts \& Bogg, 2004; Mu, 
Luo, Nickel, \& Roberts, 2016) and mental (Wright, Hopwood, \& Zanarini, 2015; Wright, Hopwood, Skodol, \& Morey, 2016) health outcomes.

Trait changes have also been associated with changes in educational, work, and interpersonal domains. For example, increases in emotional stability and conscientiousness have been linked to improved homework output (Göllner et al., 2017) and better preparation for exams (Bleidorn, 2012). Increases in extraversion, openness, and conscientiousness have been associated with occupational achievements and promotions (Le, Donnellan, \& Conger, 2014; Roberts, Caspi, \& Moffitt, 2003; Wille, Beyers, \& De Fruyt, 2012), increased job satisfaction (Le et al., 2013; Specht et al., 2011; van Aken et al., 2006; Schwaba, Robins, Grijalva, \& Bleidorn, in press), and job commitment (Hudson, Lodi-Smith, \& Roberts, 2012). Increases in emotional stability and conscientiousness promote greater relationship satisfaction (Deventer, Wagner, Lüdtke, \& Trautwein, in press; Neyer \& Lehnart, 2007; Roberts \& Bogg, 2004; Roberts \& Chapman, 2000; Robins, Caspi, \& Moffitt, 2002; Scollon \& Diener, 2006; Wagner, Lüdtke, Roberts \& Trautwein, 2014).

In summary, a large body of evidence shows that levels of and changes in personality traits predict outcomes in virtually all life domains. Notably, existing research has mostly relied on observational research designs, leaving questions concerning causality largely unanswered. More rigorous research - including experimental designs - on the sources, processes, and consequences of personality change is needed to advance our understanding of the mechanisms that underlie the observed longitudinal associations between traits and life outcomes.

\section{Sources of Personality Change}

The lifelong plasticity of personality traits and the observed patterns of normative and individual-level change have sparked fundamental debates over the sources of personality 
stability and change. In this section, we review past debates over the relative importance of genetic and environmental influences, discuss studies on life experiences and personality change, and identify important limitations of these lines of research.

\section{Nature versus Nurture}

The field has historically vacillated between two radically different positions regarding the relative importance of environmental versus genetic influences (Bleidorn, Kandler, \& Caspi, 2014). For most of the debate, the popular, but somewhat counter-intuitive, position has been that personality traits are "endogenous dispositions that follow intrinsic paths of development essentially independent of environmental influences" (McCrae et al., 2000, p. 173). According to this perspective, individual differences in personality traits - and by inference individual differences in personality trait change - are strongly influenced by genetic differences and therefore mostly immune to influences in the environment, such as interventions. A contrasting position emphasized the role of environmental influences for personality trait change, in addition to biological changes (Roberts \& Wood, 2006; Roberts, Wood, \& Smith, 2005). From this perspective, environmental influences including life experiences and purposeful interventions can lead to changes in personality traits to the degree that they modify, interrupt, or redirect people's relatively stable patterns of thoughts, feelings, strivings, and behavior.

During the past two decades, scholars have tested the differential influences of nature and nurture on individual differences in personality trait change (for reviews, see Bleidorn et al., 2014; Briley \& Tucker-Drob, 2014). The accumulated evidence converged on the conclusion that, although genetic influences on personality differences are substantial throughout the lifespan, both genetic and environmental influences contribute to both stability and change in personality traits (Bleidorn, Kandler, Riemann, Angleitner, \& Spinath, 2009; Hopwood et al., 
2011; Kandler et al., 2010). These findings refute the position that trait changes are immune to environmental influences. Personality traits, like almost every other individual difference variable in existence, have some genetic basis (Polderman et al., 2015; Turkheimer, 2000). But being influenced, in part, by some genetic mechanism does not mean that traits are immune to environmental influences.

Today, most accounts of personality development acknowledge that both genetic and environmental influences play an important role in personality stability and change. However, there is less agreement regarding the particular genetic or environmental factors that may drive changes in personality traits. Indeed, an argument can be made that the field's prolonged focus on the nature versus nurture dichotomy stalled progress towards identifying specific genetic and environmental pathways to personality change.

\section{Life Experiences and Personality Change}

While research on the specific genetic and biological sources of personality development remains rare (Lo et al., 2017; Penke \& Jokela, 2016), a growing number of studies have examined the role of specific environmental influences, typically operationalized as life experiences in the domains of love, work, and health (Bleidorn et al., 2018; Denissen, Luhmann, Chung, \& Bleidorn, 2019). For example, romantic relationship experiences - and the first romance in particular - have been associated with increases in levels of desirable traits such as emotional stability, self-esteem, and conscientiousness (Lehnart, Neyer, \& Eccles, 2010; Luciano \& Orth, 2017; Neyer \& Asendorpf, 2001; Wagner, et al., 2015). Similarly, certain work-related experiences foster personality maturation as indicated by increases in emotional stability, agreeableness, and conscientiousness (Bleidorn et al., 2013; Hudson et al., 2012). Finally, healthrelated experiences appear to be particularly relevant for personality trait changes in late 
adulthood (Kornadt, Hagemeyer, Neyer, \& Kandler, 2018; Mueller, Wagner, Smith, Voelkle, \& Gerstorf, 2018; Wagner, Ram, Smith, \& Gerstorf, 2016). Indeed, age-related declines in cognitive, physical, and sensory functioning may trigger adaptations in older adults' patterns of thoughts, feelings, strivings, and behavior to cope with these changes (Jokela, Hakulinen, SinghManoux, \& Kivimäki, 2014; Kandler et al., 2015; Mueller et al., 2018; Wagner et al., 2016).

These findings suggest that life experiences can be associated with personality change. However, the existing evidence needs to be evaluated within the broader context of studies that yielded more mixed and sometimes conflicting results (cf. Bleidorn et al., 2018). Indeed, evidence for the role of major life events, such as marriage, divorce, unemployment, or retirement is more mixed than one would expect given the apparent emotional and behavioral relevance of these events (Asendorpf \& Wilpers, 1998; Bleidorn \& Schwaba, 2018; Denissen et al., 2019; Schwaba \& Bleidorn, 2019; Specht et al., 2011; van Scheppingen, Denissen, Chung, Tambs, \& Bleidorn, 2018; van Scheppingen, Denissen, \& Bleidorn, 2018; for a review see Bleidorn et al., 2018). The inconclusive nature of the current state of evidence may be partly explained by the scope and quality of previous studies, many of which were not explicitly designed to examine the links between life events and personality change. Perhaps more important, the studies cited above typically examined the average effects of single, isolated life experiences on personality change. An implicit, but unrealistic, assumption of these studies is that life experiences - independent of the particular contexts in which they occur - would elicit the exact same trait changes in most people, at the same temporal proximity to the event. This focus on the potential main effects of discrete experiences neglects at least four important complexities in the ways people's life trajectories unfold in the context of everchanging environmental experiences. 
First, most life experiences do not occur in isolation. In fact, many experiences are correlated and tend to occur in predictable sequences. For example, young adults tend to undergo important personality changes during their college years (Chung, Robins, Trzesniewski, Noftle, Roberts, \& Widaman, 2014; Lüdtke et al., 2011; Roberts et al., 2006; Robins et al., 2001; Schwaba et al., in press). The transition to college, however, is typically associated with a host of other potentially meaningful experiences such as moving out of one's parents' home, meeting new friends and romantic partners, volunteering, employment, or exploring new identities and worldviews (Bleidorn \& Schwaba, 2017). It thus remains unclear which aspect(s) of the college experience drive changes in personality traits. Moreover, successful graduation from college opens the door to a whole new set of life experiences such as paid employment, which, in turn, entail access to new experiences such as promotion or unemployment. Similarly, marriage can be considered a gateway experience to various other life events such as parenthood, divorce, or widowhood. These examples illustrate how difficult (and possibly misleading) it is to disentangle different life events and study them in isolation as both minor and major life experiences occur in certain contexts and in relation to other experiences that may either promote stability or trigger change in personality traits.

A second complexity involves the fact that most life experiences are not random. People tend to evoke, select, or create certain experiences, often on the basis of their genetically influenced personality traits (Scarr \& McCartney, 1983). In other words, genetically influenced traits may predispose individuals to certain life experiences which, in turn, may lead to changes in those or other personality characteristics (e.g., Wille \& De Fruyt, 2014). For example, people with high levels of neuroticism tend to experience more negative and stressful life events, which may, in turn, reinforce their neurotic outlook on life (e.g., Borghuis et al., in press). Consistent 
with the corresponsive principle (cf. Roberts et al., 2008), numerous studies have shown that environmental experiences - and even seemingly uncontrollable events such as accidents or job loss - are under some genetic influence (Kandler, Bleidorn, Riemann, Angleitner, \& Spinath, 2012; Kendler \& Baker, 2007). As such, we cannot rule out that putative environmental causes of personality change may reflect, at least in part, both genetic and environmental influences (Briley, Livengood, \& Derringer, 2018).

Third, it is implausible to assume that life experiences elicit the exact same responses in most people. Indeed, the assumption that people differ in how they perceive and react to environments is at the heart of the definition of personality. For example, although most people consider divorce as a stressful and aversive life experience, some people consider divorce as an opportunity to overcome the ongoing strains of an unhappy marriage (Amato, 2000). The degree to which the experience of this event may elicit negative vs. positive changes in people's selfesteem, adjustment, or personality may thus vary from person to person, depending on a variety of protective and risk factors (Luciano \& Orth, 2017). In short, there may be different psychological implications for different individuals as they navigate certain life experiences. Accounting for person-environment interactions requires researchers to go beyond the question of which environmental sources matter by asking who is most likely affected by which environmental conditions and why (Kandler \& Ostendorf, 2016).

A fourth complexity involves the implicit assumption that personality trait changes unfold gradually over long time periods, as reflected in long lags between only few personality assessments of most existing panel studies. This assumption, however, is untested. Indeed, changes in certain traits and in response to certain experiences may occur rapidly (Roberts et al., 2017) and potentially fade with time. As we will discuss in more detail below, common 
longitudinal designs with few assessment waves and long lags between assessments are at risk of obscuring temporary or non-linear changes in traits.

In summary, previous attempts to study the environmental underpinnings of personality traits have failed to account for the complex ways in which persons and environments interact in producing stable or changing patterns of thoughts, feelings, and behavior. Firmer conclusions regarding the sources of personality change become more likely to the degree that the field can move toward more flexible and nuanced frameworks for studying the sources of personality change. Critical for these frameworks will be a thorough understanding of the processes underlying personality change.

\section{Personality Change Processes}

The conceptualization of personality traits as dynamic and potentially changeable constructs has led to a great deal of speculation about the underlying process of personality change. Recent theoretical accounts - while emphasizing different details - aim to explain how changes in personality traits unfold over time; how external sources such as life events can get under the skin and lead to change in traits; and why people differ in their individual trajectories when exposed to relevant sources of personality change (Back, Baumert et al., 2011; Geukes, van Zalk, \& Back, 2018; Hennecke, Bleidorn, Denissen, \& Wood, 2014; Hopwood, 2018; Roberts \& Jackson, 2008; Wrzus \& Roberts 2017).

\section{Key Principles of Personality Process Models}

In this section, we review recent process models of personality change with a focus on key principles that are accentuated across different theories. First, all accounts define personality development processes as series of interlinked steps through which a person's traits are either changed or stabilized (e.g., Baumert et al., 2017). In other words, personality change processes 
are typically assumed to unfold over a certain period of time. The exact timing of these processes may vary across individuals, states, and traits.

Second, a key ingredient of all process models are personality states - the momentary manifestations of traits that refer to specific thoughts, feelings, strivings, and behaviors (e.g., Hennecke et al., 2014; Geukes et al., 2018; Roberts, 2018; Wrzus \& Roberts 2017). Unlike traits that are thought to generalize across domains and situations, states are thought to vary across situations as a function of personal and environmental triggers. People frequently act in ways that are inconsistent with their dispositional tendencies as evidenced by a less than perfect relation between self-reported states and traits (correlations are typically $r=.5$ and lower; Fleeson, 2001). Moreover, temporary state fluctuations around one's average tendency (i.e., trait) are common. Contemporary process models of personality change make a distinction between states and traits while also acknowledging their intimate linkage, which is critical to understanding how traits might change.

Third, the expression of personality states is contingent on certain environmental and individual constraints (Bleidorn \& Denissen, 2015; Hennecke et al., 2014; Wrzus \& Roberts, 2017). The environmental context provides natural affordances and boundaries for what people can experience, pursue, and do in any moment. For example, urban (vs. rural) environments may afford more possibilities to engage with arts and music, explore new restaurants, or interact with people from different social, cultural, and ethnic backgrounds. Urban environments may thus be particularly attractive to people high in openness (Jokela, Bleidorn, Lamb, Gosling, \& Rentfrow, 2015). People's genetically-based predispositions and self-concepts may further influence their momentary state expression. For example, it is well-established that individuals differ in their stress reactivity and show more or less negative affect in response to adverse or otherwise 
stressful life experiences (Wright, Hopwood, \& Simms, 2015). Similarly, individuals might cope differently when faced with stress depending on their generalized self-concepts and identity (Klimstra \& Denissen, 2017).

Fourth, the expression of new or modified personality states may, if sufficiently repeated, condense into habits, and generalize across domains. This kind of process may be explicit or implicit. In perhaps the most intuitive explicit model, habit changes over time may lead to changes in people's generalized self-concepts, their biologically-based response thresholds (e.g., pliable and elastic epigenetic systems; cf. Roberts, 2018), and eventually translate into enduring trait changes which then serve as new defaults for the expression of states (Baumert et al., 2017; Geukes et al., 2018; Hennecke et al., 2014; Hopwood, 2018; Roberts \& Jackson, 2008; Smith \& DeCoster, 2000; Wood, 2017; Wrzus \& Roberts, 2017; Wrzus, 2018). For instance, many people desire to be less neurotic (Hudson \& Fraley, 2015), and some people may actually be able to effectively lower their momentary state levels of neurotic thoughts, feelings, strivings, and behaviors (e.g., as a result of psychotherapy, cf. Roberts et al., 2017). Over time, such modified states may turn into habits and generalize to a broad range of situations. State and habit changes can be of emotional, behavioral, motivational or cognitive nature. For instance, cognitive approaches to psychotherapy focus on changing thoughts, exposure-based approaches focus on changing feelings, and skills-training approaches focus on changing behavior. In all three cases, the idea is that a person's habit change in one domain can spread to changes in the other domains, and might eventually lead to changes across all domains. To the degree that the person and others also change their internalized beliefs about that person, we would be able to measure these changes with self- or informant report personality questionnaires. 
Fifth, changes in different personality state modalities (e.g., thoughts, behaviors, feelings) may occur as parallel processes that reinforce each other in a corresponsive fashion. For example, changes in personality relevant behaviors may lead to changes in people's thoughts about themselves (i.e., their self-concept) which may, in turn, promote self-concept confirming changes in behaviors (Borghuis et al., in press; Roberts \& Wood, 2006). To illustrate, a person who starts engaging in a variety of cultural activities such as music, literature, or theatre may increasingly consider openness to experience, and aesthetic interests in particular, as important aspects of their self-concept. These changes may lead them to seek out other possibilities to express their openness; such as reading poems or visiting the opera, which may further consolidate their self-concept as an open and aesthetically minded person (cf. Schwaba et al., 2018).

In summary, we propose that personality trait changes most likely unfold as a consequence of enduring modifications in a range of people's personality states that result in new systems of stable state regularities and adjust peoples biological and self-concept constraints. This may also help explain why people do not change their personality traits more often. Having a desire to change one's personality traits is not sufficient if a person lacks the capacity or opportunity to implement appropriate further state changes; and having both the desire and the opportunity to change may still not result in enduring personality trait change if changes are not shown habitually. Finally, researchers will only be able to assess these changes with personality measures that rely on a person's sense of themselves if people also modify their self-concepts.

\section{Research on Personality Change Processes}

These principles provide a set of testable hypotheses for the likelihood that certain environmental factors or interventions may result in personality trait changes for certain 
individuals. Yet, few studies have put these principles to a test (for exceptions, see Borghuis et al., in press; Hutteman et al., 2015). One reason for the scarcity of personality process studies is that these studies are typically cost- and data-intensive. For example, the examination of momentary shifts in personality states and the formation of relatively stable trait patterns requires frequent or even continuous assessments of thoughts, feelings, strivings, and behaviors as they unfold in people's daily lives or in response to certain experiences or interventions. Such studies are not only expensive and burdensome but require researchers to process large amounts of data using advanced statistical techniques capable of picking up relevant but presumably small effects.

Moreover, conceptual and methodological issues that have hampered progress in this area. In particular, researchers need to refine their hypotheses about the links between experiences and particular state modalities (e.g., thoughts, behaviors, strivings, emotions), the interplay between different states over time, and the processes by which state changes translate into enduring trait changes (Geukes et al., 2018).

Relatedly, little is known about the frequency and time scale with which state and trait changes unfold (cf. Hopwood, Bleidorn, \& Wright, 2019). A better understanding of when and how people adjust their state processes and habits will be essential for developing valid and costefficient study designs. Moreover, future research will need to apply a more diversified assessment toolbox (Geukes, van Zalk, \& Back, 2017; Wrzus \& Mehl, 2015) as the overreliance on self-report questionnaires has provided a rather narrow window into personality change processes. As we outline in more detail below, the development of new measures designed to assess the momentary manifestation of different state modalities over time and in relation to a wide range of experiences will be critical to advance our understanding of personality change 
processes. In other words, the field needs a new paradigm. In the next section, we present the broad outlines for a novel framework for studying personality change that integrates a number of isolated suggestions for reform currently available in the literature, with a particular emphasis on relevant methodological and conceptual challenges.

\section{Longitudinal Experience-Wide Association Studies (LEWAS)}

Similar to the field of genetics in which Genome-Wide Association Studies (GWAS) have replaced candidate gene and genetic linkage studies (e.g., van den Berg et al., 2016), we envision a paradigmatic shift in personality research towards Longitudinal Experience-Wide Association Studies (LEWAS) designed to derive maps of experiences, behaviors, and life paths that may lead to changes in personality traits for certain individuals with a particular genotypic make-up.

We acknowledge that GWAS has not proven to be the royal road to understanding genetic influences on behavior, and emphasize that there are important differences between GWAS and the proposed research framework. We use the term LEWAS as a loose analogy, with three main connections to GWAS. First, just as GWAS studies endeavor to sample the genome comprehensively, we suggest that transformative progress in understanding the sources and processes underlying personality change will require efforts to assess personal and environmental factors as comprehensively as possible. Second, just as GWAS require sample sizes of magnitude larger than had been the norm in behavioral genetic research to detect small effects of genes and effects of rare genetic variants, LEWAS will also require much more extensive sampling of both people and variables to detect the cumulative influence of diverse experiences. Third, just as GWAS are too resource intensive to be accomplished within a single research lab, we likewise envision LEWAS that combine the expertise and resources of teams of 
investigators. In what follows, we describe the four pillars of LEWAS - timing, samples, measures, and experiments - to provide a framework for future research on personality change (see Figure 1).

\section{Timing}

The majority of existing longitudinal studies to date have been designed under the assumption that personality traits do not change at all or at least not quickly. As such, there was little or no need to assess personality frequently. A review of existing large-scale longitudinal personality studies also reveals a trade-off between large samples and rigorous longitudinal designs. For example, representative panel studies such as the German Socioeconomic Panel (GSOEP; see e.g., Wortmann et al., 2012) offer large samples; however, these studies were not designed to study personality change. Consequently, assessment waves are usually too infrequent and too widely spaced (e.g., only 3 Big Five assessment waves spaced 4 years apart are available in the latest GSOEP version) to allow researchers to study personality change with the necessary temporal resolution.

Recent research showed that personality traits can and do change relatively quickly, at least in contrast to prior expectations (Roberts et al., 2017), but we still lack key data for pressing developmental questions because we have assessed personality too infrequently. Moreover, available data are insufficient to fully inform the varieties of shapes and forms of individual change trajectories. LEWAS that are designed to capture these different temporal dynamics while ruling out potential confounding influences would have more power to capture personality change in the context of life experiences (Luhmann, Orth, Specht, Kandler, \& Lucas, 2014). Three features are particularly important for a better understanding of the pace and timing of personality change. 
First, a crucial feature that is missing from many previous studies on personality change is the availability of multiple assessments of personality states and traits before the beginning of a change process. Prospective designs including multiple pre-event assessments are needed to control for baseline differences that could explain putative changes in response to environmental influences (Luhmann et al., 2014). As discussed above, a divorce is the legal outcome of a process of deteriorating marital quality and marital separation that typically starts long before the actual divorce (Block, Block, \& Gjerde, 1986). A longitudinal study of personality change in the context of marital dissolution should thus begin several years before the actual divorce to ensure that the entire change process is captured (cf. Bleidorn, Schwaba, Denissen, \& Hopwood, 2019; Denissen et al., 2019).

Second, longitudinal studies should include multiple assessments of personality, experiences, and outcomes at different frequencies. Multiple assessment waves are necessary to capture non-linear change or discontinuous change patterns (cf. Schwaba \& Bleidorn, 2019; Luhmann \& Eid, 2012). A minimum of four assessments are required to detect a quadratic effect, and even more assessments are needed to model other nonlinear (cubic or even multilevel polynomial) slopes accurately or to model more complex discontinuous or piecewise change patterns (van Scheppingen et al., 2018). Given that the time scale for personality change is largely unknown - particularly in association with environmental changes - there should be an emphasis on more frequent assessments with sufficiently short lags between assessments to explore any plausible changes in states and traits with sufficiently high temporal resolution. Indeed, more research on the timeline at which changes in different state modalities translate into measurable changes in trait levels is needed to derive more specific recommendations for the frequency and timing of assessment waves in longitudinal studies (cf. Figure 1). 
Third, the intervals between assessments should be sufficiently short to detect changes in states and traits. Short lags between assessment waves are particularly relevant if researchers are interested in how momentary or episodic changes in states might build up to more enduring trait changes, as described above. Indeed, longer lags between assessment waves may obscure relevant short-term processes and potentially lead to an overestimation of personality stability and ambiguity in the underlying change process. A high temporal resolution of assessments is thus particularly important during periods when change is expected (e.g., during an intervention or in the context of a major life experience).

The inclusion of assessment bursts into longitudinal designs can be a useful strategy to increase the frequency of assessments of momentary thoughts, feelings, strivings, and behavior during such periods (Trull \& Ebner-Priemer, 2013; Wrzus \& Mehl, 2015). Such measurement burst designs allow researchers to hone in on times when change is expected, and relate those times to more general or slower-moving personality change trends (Sliwinski, 2008). The specific number, timing, and frequency of both assessments per burst and measurement bursts within a longitudinal design may vary across traits, environmental conditions, and individuals. Ideally, the inclusion of measurement bursts into LEWAS should be based on either theoretical models or empirical evidence rather than statistical concerns such as equidistance between assessments or convenience, as has been the norm in past measurement burst studies. For example, researchers interested in personality change in the job context may time their assessments during the workweek, ideally centered on a theoretically relevant event, such as promotion, or in response to certain recurring experiences such as interactions with customers or supervisors.

\section{Samples}


In GWAS, individual genetic variants typically explain less than $1 \%$ of the heritability in individual differences on most traits (Sullivan, 2012). Similarly, the effects of individual life experiences on personality change may be small, particularly when averaged across people. However, when experiences are considered together and in light of individual environmental contexts, they may have more profound effects on people's personality trajectories. Analogous to GWAS, large samples will be crucial to identify these presumably small effects with sufficient statistical power. In addition to large numbers, LEWAS samples should be diverse and include relevant comparison groups.

Samples should be representative of the population studied and diverse to ensure the generalizability of the results. The vast majority of research on personality change comes from WEIRD (Henrich, Heine, \& Norenzayan, 2010) samples in Western Europe and North America, regions that comprise only $15 \%$ of the world population. Very few studies have explored cultural differences in personality trait development (Bleidorn et al., 2013; McCrae et al., 2000). These studies have typically used cross-sectional designs to examine Big Five mean-level differences across different age groups. A systematic examination of longitudinal changes in personality traits across a large and diverse set of cultures has yet to be undertaken. Indeed, such an analysis would provide important information about the universal and culture-specific mechanisms that might drive changes in personality traits.

It is also important that samples include subsamples of meaningful comparison groups. An advantage of large, representative, and diverse samples is that they include people who experience a variety of life experiences. The comparison of people who do and do not experience certain life experiences is critical to rule out third-variable influences such as age-graded maturation or historical effects. In their simplest form, comparison groups can consist of all 
study participants who have not been exposed to the influence of interest (e.g., Denissen et al., 2019). However, these naturally existing comparison groups likely differ from those who experienced the event in systematic ways (Bleidorn et al., 2018). Ideally, comparison groups would be matched on relevant demographic and psychological characteristics (e.g., using propensity score matching; Thoemmes \& Kim, 2011; van Scheppingen et al., 2016; Wagner et al., 2015) or even on their shared genetic makeup (e.g., in quasi-causal twin-difference designs; Zapko-Willmes, Riemann, \& Kandler, 2018). Indeed, a particularly well-matched control group would consist of monozygotic twin siblings who share both a common genetic make-up and a similar rearing environment (McGue, Osler, \& Christensen, 2010; Turkheimer \& Harden, 2014).

\section{Measurement}

Self-report trait questionnaires are the most common assessment method in personality research. Moreover, personality researchers tend to prefer a somewhat narrow range of popular self-report instruments. A broader and more flexible set of tools for assessing not only traits but also states and life experiences will be a critical feature of LEWAS. We see at least three pressing tasks that need to be addressed to advance the measurement of personality change.

First, the widespread use of popular self-report measures has certain advantages, such as cost-efficiency, comparability across studies, and the relative sensitivity of self-report to individual differences in the self-concept (Paulhus \& Vazire, 2007). However, the over-reliance on certain self-report measures limits the inferences that can be drawn from existing research on personality change. Self-report measures rely heavily on a person's sense of themselves, and thus may diverge from other assessment approaches that more directly target factors such as typical behaviors or social reputations that are at least partly outside of the person's awareness. In addition to more general problems such as rater-specific response biases, some features of 
common self-report questionnaires may compromise the assessment of change in personality traits. Specifically, personality trait measures are typically developed in cross-sectional data to capture the structure of individual differences. It remains unclear whether these measures are also suitable for capturing the structure of intraindividual changes, or to measure personality processes (Adolf, Schuurman, Borkenau, Borsboom, \& Dolan, 2014; Hamaker, Schuurman, \& Zijlmans, 2017). Moreover, to the degree that people compare themselves with certain reference groups (e.g. younger vs. older individuals) when processing self-report items (Credé, Bashshur, \& Niehorster, 2010; Wood, Brown, Maltby, \& Watkinson, 2012), researchers may over- or underestimate change in personality traits.

Second, the field lacks validated instruments that are explicitly tailored to the assessment of personality states (Geukes et al., 2017; Wrzus \& Mehl, 2015; Zimmermann et al., 2019). Ideally, such instruments would allow researchers to assess different state modalities (e.g., emotional, behavioral, motivational, cognitive) continuously over time. Most existing approaches exclusively include self-reported state measures (see, Geukes et al., 2019, for an exception) and, thus, can capture people's explicit thoughts, feelings and strivings but are not well suited to record momentary behaviors (Back \& Egloff, 2009) or more implicit mental states (Back \& Nestler, 2017). Recent technological developments such as mobile sensing and ambulatory assessment offer some promising avenues for the more comprehensive development of high-resolution state measures. However, several psychometric, ethical, and data-analytic challenges need to be addressed before such measures can be implemented in LEWAS (Geukes et al., 2017; Harari et al., 2017).

A third challenge concerns the lack of viable measures of life experiences. Given that life experiences can be correlated (e.g., marriage and parenthood), it will be important to assess a 
broad range of different life experiences that can be connected to one another to gain a better sense of how personality traits and experiences co-develop over time. This would include an assessment not only of major life experiences such as graduations, marriages, or retirements, but also of more minor contextual factors relevant to the person's environment, such as relationship experiences, job satisfaction, health variables, daily hassles, and the contours of particular situations or interactions (e.g., Rauthmann, Sherman, \& Funder, 2015). In addition to assessing the relatively objective occurrence of events, it will also be important to capture people's subjective experience (e.g., threatening, pleasant, stimulating) of events (Roberts et al., 2005). Associations between personality traits and each of these factors have been studied in isolation, but all of these factors have not yet been integrated empirically in longitudinal data in order to examine the complex connections between personality change and a wide range of life experiences.

Two strategies can be used to advance the assessment of personality change processes and life experiences. The more modest strategy would involve the improvement of existing selfreport instruments so they can better serve research on personality change across the lifespan and validly assess samples from different cultures. For example, items from existing personality instruments can be evaluated for their sensitivity to assess changes at different ages, or for their appropriateness as trait indicators across different ages, and refined as necessary (Olaru, Schroeders, Wilhelm, \& Ostendorf, in press).

The more ambitious strategy would involve the development of new instruments that are specifically tailored to the assessment of personality states, traits, and life experiences over time, ideally involving complementary assessment methods such as informant reports (Oltmanns, Jackson, \& Oltmanns, in press; Vazire, 2006), interaction partner reported behavior (Geukes et 
al., 2019), digital footprints of behavior (Adjerid \& Kelley, 2018; Bleidorn \& Hopwood, 2019; Kosinski, Matz, Gosling, Popov, \& Stillwell, 2015), mobile sensing of behavior and contexts in real time (Beierle et al., 2018; Harari et al., 2017), narratives (Dunlop, 2015), behavioral tasks and observational measures (Back, Schmukle, \& Egloff, 2009; Borkenau, Mauer, Riemann, Spinath, \& Angleitner, 2004; Funder, Furr, \& Colvin, 2000; Mihura et al., 2013; Sadler et al., 2010) and biological markers (Briley et al., 2018). In addition to providing more reliable assessments of relevant constructs, the observation of discrepancies between different assessment methods may further lead to new insights regarding the sources and processes of personality change. Assessment methods other than self-report are particularly crucial for a rigorous evaluation of personality interventions and experimental paradigms, a relatively novel line of work that we turn to next.

\section{Experiments}

Studies of naturally occurring personality change should be complemented by experimental and quasi-experimental designs, perhaps implemented in sub-samples of largescale longitudinal studies, that can strengthen causal inferences. Between-person randomized controlled trials (RCTs) and within-person ABAB designs are routinely used in medical and other sciences to examine whether an outcome can be altered by specific treatment protocols. Personality interventions have been studied mostly in the context of mental health treatments where personality has been assessed as a secondary outcome. These studies suggest that clinical interventions can lead to lasting changes in personality traits, sometimes substantially and rather quickly (Roberts et al., 2017). Use of psychotropic drugs (e.g., antidepressants or psychedelics) has also been found to be associated with long-term changes in personality (Erritzoe et al., 2018; Ilieva, 2015). 
In contrast to the rich literature on clinical interventions, research on non-clinical interventions has only recently taken root in the field of personality psychology (Allemand \& Flückiger, 2017). For example, a mindfulness intervention for medical students resulted in personality trait changes in the traits of conscientiousness, agreeableness, empathy, and emotional stability (Krasner et al., 2009). Similarly, a cognitive training intervention for older adults was also associated with changes in openness to experience (Jackson, Hill, Payne, Roberts, \& Stine-Morrow, 2012). These studies provide initial evidence that personality traits can be changed through active intervention. However, more research is needed to develop and validate treatment protocols for personality change interventions (Stieger et al., 2018). In addition, future intervention studies should examine the outcomes of induced personality changes. A lack of associations with relevant outcomes would suggest that induced personality changes are functionally different from naturally occurring personality variation between individuals.

Quasi-experimental study designs take advantage of variation in causal factors that are outside the person's influence but are not controlled by research protocols (Akee, Copeland, Costello, \& Simeonova, 2018). These factors can be used to yield more robust estimates for causal associations. For example, research on personality change in response to unemployment could be complemented with data on factory closings and other organizational changes that originate outside the person's own actions and thus are unlikely to be confounded by third variables or reverse causality (Gathergood, 2013). Methods such as instrumental-variable regression and regression discontinuity can be used to analyze quasi-experimental data (Angrist $\&$ Pischke, 2009). Of course, the research questions available for quasi-experimental designs tend to be opportunistic, as the quasi-experimental treatments are not devised by researchers but 
happenstance. Despite their limitations, more quasi-experimental designs should be used to examine personality change in order to evaluate how closely the results from traditional longitudinal studies match with the results from more robust causal methods.

\section{Summary}

We believe that personality psychology is poised to have a profound impact given the powerful implications of personality change for individual growth and societal well-being (Bleidorn, Hill, et al., in press). However, a paradigm shift in personality change research is needed to fulfil this potential. In the field of genetics, major progress was achieved through the advent of biobanks, the development of more efficient assessment and statistical methods, and perhaps most importantly - the emergence of collaborative consortia to conduct more rigorous, high quality studies that sampled the genome comprehensively (e.g., Sullivan, 2012). In establishing PCC - a consortium for the study of personality change - we aim to promote similar developments in the area of personality development.

In this paper we outlined the characteristics of LEWAS, a new generation of studies that aim to address the major challenges in contemporary research on personality change. LEWAS would represent a paradigm shift in personality change research featuring assessments of multiple potential sources of change related to the person, their genes, and their environments; large, diverse, and representative samples; specific theoretical models of processes that underlie

personality change; frequent, multi-method assessments; and embedded experimental or burst designs targeting specific mechanisms.

We believe that the success of such studies will depend on combining the resources of researchers with different skill sets and areas of expertise. Funding for such studies and their ultimate impact will be more likely to the degree that personality psychologists are better able to 
publicize the importance of personality change to funders, policy makers, and other influential groups. Ultimately, we hope these efforts contribute to transformative personality research that tangibly advances theory and public welfare. 


\section{References}

Adjerid, I., \& Kelley, K. (2018). Big data in psychology: A framework for research advancement. American Psychologist, 73, 899-917.

Adolf, J., Schuurman, N. K., Borkenau, P., Borsboom, D., \& Dolan, C. V. (2014). Measurement invariance within and between individuals: A distinct problem in testing the equivalence of intra- and inter-individual model structures. Frontiers in Psychology, 5, 883.

Akee, R., Copeland, W., Costello, E. J., \& Simeonova, E. (2018). How does household income affect child personality traits and behaviors? The American Economic Review, 108, 775827.

Allemand, M., \& Flückiger, C. (2017). Changing personality traits: Some considerations from psychotherapy process-outcome research for intervention efforts on intentional personality change. Journal of Psychotherapy Integration, 27, 476-494.

Allport, G. W. (1961). Pattern and growth in personality. Oxford, England: Holt, Reinhart \& Winston.

Amato, P. R. (2000). The consequences of divorce for adults and children. Journal of Marriage and Family, 62, 1269-1287.

Anderson, C., John, O. P., Keltner, D., \& Kring, A. M. (2001). Who attains social status? Effects of personality and physical attractiveness in social groups. Journal of Personality and Social Psychology, 81, 116-132.

Angrist, J. D., \& Pischke, J. S. (2009). Mostly harmless econometrics: An empiricist's companion. Princeton: Princeton University Press. 
Asendorpf, J. B., Penke, L. \& Back, M. D. (2011). From dating to mating and relating: Predictors of initial and long-term outcomes of speed-dating in a community sample. European Journal of Personality, 25, 16-30.

Asendorpf, J. B., \& Wilpers, S. (1998). Personality effects on social relationships. Journal of Personality and Social Psychology, 74, 1531-1544.

Ashton, M. C., \& Lee, K. (2007). Empirical, theoretical, and practical advantages of the HEXACO model of personality structure. Personality and Social Psychology Review, 11, $150-166$.

Back, M. D., Baumert, A., Denissen, J. J. A., Hartung, F.-M., Penke, L., Schmukle, S. C., Schönbrodt, F. D., Schröder-Abé, M., Vollmann, M., Wagner, J., \& Wrzus, C. (2011). PERSOC: A unified framework for understanding the dynamic interplay of personality and social relationships. European Journal of Personality, 25, 90-107.

Back, M. D. \& Egloff, B. (2009). Yes we can! A plea for direct behavioral observation in personality research. European Journal of Personality, 23, 403-405.

Back, M., \& Nestler, S. (2017). Dual-process approaches to personality. In R. Deutsch, B. Gawronski, \& W. Hofmann (Eds), Reflective and impulsive determinants of human behavior (pp. 137-154). New York, NY: Routledge.

Back, M. D., Schmukle, S. C. \& Egloff, B. (2009). Predicting actual behavior from the explicit and implicit self-concept of personality. Journal of Personality and Social Psychology, $97,533-548$.

Back, M. D., Schmukle, S. C., \& Egloff, B. (2011). A closer look at first sight: Social relations lens model analysis of personality and interpersonal attraction at zero acquaintance. European Journal of Personality, 25, 225-238. 
Borkenau, P., Mauer, N., Riemann, R., Spinath, F. M., \& Angleitner, A. (2004). Thin slices of behavior as cues of personality and intelligence. Journal of Personality and Social Psychology, 86, 599-614.

Baumert, A., Schmitt, M., Perugini, M., Johnson, W., Blum, G., Borkenau, P., Costantini, G., ... Wrzus, C. (2017). Integrating personality structure, personality process, and personality development. European Journal of Personality, 31, 503-528.

Beierle, F., Tran, V. T., Allemand, M., Neff, P., Schlee, W., Probst, T., . . Zimmermann, J. (2018). Context data categories and privacy model for mobile data collection apps. Procedia Computer Science, 134, 18-25.

Bleidorn, W. (2012). Hitting the road to adulthood: Short-term personality development during a major life transition Personality and Social Psychology Bulletin, 38, 1594-1608.

Bleidorn, W. (2015). What accounts for personality maturation in early adulthood? Current Directions in Psychological Science, 24, 245-252.

Bleidorn, W., Denissen, J.J.A. (2015). Virtues in action - the new look of character traits. British Journal of Psychology, 106, 700-723.

Bleidorn, W., Hill, P. L., Back, M.D., Denissen J.J.A., Hennecke, M., Hopwood, C.J., ... \& Roberts, B. W. (2019). The policy relevance of personality traits. Manuscript accepted for publication.

Bleidorn, W. \& Hopwood, C. J.: Stability and Change in Personality Traits Over the Lifespan, McAdams, D. P. Shiner, R., Tackett, J., (eds.), Handbook of Personality Development. Vol. 1, Guilford, New York. pp. 237-252.

Bleidorn, W. \& Hopwood, C. J. (2019). Using machine learning to advance personality assessment and theory. Personality and Social Psychology Review, 23, 190-203. 
Bleidorn, W., Hopwood, C. J., Lucas, R. E. (2018). Life events and personality trait change. Journal of Personality, 86, 83-96.

Bleidorn, W., Hopwood, C. J., Ackerman, R. A., Witt, E. A., Kandler, C., Riemann, R., Samuel, D. B., \& Donnellan, M. B. (in press). The healthy personality from a basic trait perspective. Journal of Personality and Social Psychology.

Bleidorn, W., Kandler, C., \& Caspi, A. (2014). The behavioral genetics of personality development in adulthood - Classic, contemporary, and future trends. European Journal of Personality, 28, 244-255.

Bleidorn, W., Kandler, C., Riemann, R., Angleitner, A., \& Spinath, F.M. (2009). Patterns and sources of adult personality development: Growth curve analyses of the NEO-PI-R scales in a longitudinal twin study. Journal of Personality and Social Psychology, 97, 142-155.

Bleidorn, W., Klimstra, T.A., Denissen, J.J.A., Rentfrow, P.J., Potter, J., \& Gosling, S.D. (2013). Personality maturation around the world: A cross-cultural examination of Social Investment Theory. Psychological Science, 24, 2530-2540.

Bleidorn, W. \& Schwaba, T. (2017) Personality development in emerging adulthood, Specht, J. (ed.): Personality Development Across the Lifespan, 93-52, Elsevier, Oxford.

Bleidorn, W. \& Schwaba, T. (2018). Retirement is associated with change in self-esteem. Psychology and Aging, 33, 586-594.

Block, J. H., Block, J., \& Gjerde, P. F. (1986). The personality of children prior to divorce: A prospective study. Child Development, 57, 827-840.

Bogg, T., \& Roberts, B. W. (2004). Conscientiousness and health-related behaviors: a metaanalysis of the leading behavioral contributors to mortality. Psychological Bulletin, 130, 887. 
Borghuis, J., Bleidorn, W. Sijtsma, K., Branje, S. Meus, W. H. J., Denissen, J. J. A. (in press). Longitudinal associations between trait neuroticism and negative daily experiences in adolescence. Journal of Personality and Social Psychology.

Borghuis, J., Denissen, J. J. A., Oberski, D., Sijtsma, K., Meeus, W. H. J., Branje, S., . . Bleidorn, W. (2017). Big Five personality stability, change, and co-development across adolescence and early adulthood. Journal of Personality and Social Psychology, 113, 641-657.

Briley, D. A., \& Livengood, J., \& Derringer, J. (2018). Behavior genetic frameworks of causal reasoning for personality psychology. European Journal of Personality, 32, 202-220.

Briley, D. A., \& Tucker-Drob, E. M. (2014). Genetic and environmental continuity in personality development: A meta-analysis. Psychological Bulletin, 140, 1303.

Costa Jr, P. T., McCrae, R. R., \& Löckenhoff, C. E. (2019). Personality across the life span. Annual Review of Psychology, 70, 423-448.

Chow, P. I., \& Roberts, B. W. (2014). Examining the relationship between changes in personality and changes in depression. Journal of Research in Personality, 51, 38-46.

Chung, J. M., Robins, R. W., Trzesniewski, K. H., Noftle, E. E., Roberts, B. W., \& Widaman, K. F. (2014). Continuity and change in self-esteem during emerging adulthood. Journal of Personality and Social Psychology, 106, 469.

Credé, M., Bashshur, M., \& Niehorster, S. (2010). Reference group effects in the measurement of personality and attitudes. Journal of Personality Assessment, 92, 390-399.

De Fruyt, F., Bartels, M., Van Leeuwen, K. G., De Clercq, B., Decuyper, M., \& Mervielde, I. (2006). Five types of personality continuity in childhood and adolescence. Journal of Personality and Social Psychology, 91, 538-552. 
Denissen, J.J.A., Bleidorn, W., Hennecke, M., Luhmann, M., Orth, U., Specht, J., \& Zimmermann, J. (2018). Uncovering the power of personality to shape income. Psychological Science, 29, 3-13.

Denissen, J.J.A., Luhmann, M. Chung, J.M. Bleidorn, W. Transactions between life events and personality traits across the adult lifespan (2019). Journal of Personality and Social Psychology, 116, 612-633.

Denissen, J. J. A., Ulferts, H., Lüdtke, O., Muck, P. M., \& Gerstorf, D. (2014). Longitudinal transactions between personality and occupational roles: A large and heterogeneous study of job beginners, stayers, and changers. Developmental Psychology, 50, 1931-1942.

DeYoung, C. G. (2015). Cybernetic big five theory. Journal of Research in Personality, 56, 3358.

Dudley, N. M., Orvis, K. A., Lebiecki, J. E., \& Cortina, J. M. (2006). A meta-analytic investigation of conscientiousness in the prediction of job performance: Examining the intercorrelations and the incremental validity of narrow traits. Journal of Applied Psychology, 91, 40-57.

Dunlop, WL (2015), Contextualized Personality, Beyond Traits. European Journal of Personality, 29, 310-325.

Erritzoe, D., Roseman, L., Nour, M. M., MacLean, K., Kaelen, M., Nutt, D. J., \& Carhart-Harris, R. L. (2018). Effects of psilocybin therapy on personality structure. Acta Psychiatrica Scandinavica, 138, 368-378.

Deventer, J., Wagner, J., Lüdtke, O., \& Trautwein, U. (2019). Are personality traits and relationship characteristics reciprocally related? Longitudinal analyses of codevelopment 
in the transition out of high school and beyond. Journal of Personality and Social Psychology, 116, 331-347.

DeYoung, C. G. (2015). Cybernetic big five theory. Journal of Research in Personality, 56, 3358.

Fleeson, W. (2001). Toward a structure-and process-integrated view of personality: Traits as density distributions of states. Journal of Personality and Social Psychology, 80, 10111027.

Fujita, F., \& Diener, E. (2005). Life satisfaction set point: stability and change. Journal of Personality and Social Psychology, 88, 158.

Funder, D. C. (1991). Global traits: A Neo-Allportian approach to personality. Psychological Science, 2, 31-39.

Funder, D. C., Furr, R. M., \& Colvin, C. R. (2000). The Riverside Behavioral Q-Sort: A tool for the description of social behavior. Journal of Personality, 68, 451-489.

Gathergood, J. (2013). An instrumental variable approach to unemployment, psychological health and social norm effects. Health Economics, 22, 643-654.

Geukes, K., Breil, S. M., Hutteman, R., Nestler, S., Küfner, A.C.P., Back, M.D. (2019). Explaining the longitudinal interplay of personality and social relationships in the laboratory and in the field: The PILS and the CONNECT study. PlosOne, 14, e0210424.

Geukes, K., van Zalk, M. H. W., \& Back, M. D. (2017). Analyzing Processes in Personality Development. In J. Specht (Ed.). Personality development across the lifespan (pp. 455472). San Diego: Elsevier. 
Geukes, K., van Zalk, M., \& Back, M. D. (2018). Understanding personality development: An integrative state process model. International Journal of Behavioral Development, 42, $43-51$.

Göllner, R., Damian, R. I., Rose, N., Spengler, M., Trautwein, U., Nagengast, B., \& Roberts, B. W. (2017). Is doing your homework associated with becoming more conscientious? Journal of Research in Personality, 71, 1-12.

Hamaker, E. L., Schuurman, N. K., \& Zijlmans, E. A. O. (2017). Using a few snapshots to distinguish mountains from waves: Weak factorial invariance in the context of trait-state research. Multivariate Behavioral Research, 52, 47-60.

Hampson, S. E., Goldberg, L. R., Vogt, T. M., \& Dubanoski, J. P. (2007). Mechanisms by which childhood personality traits influence adult health status: educational attainment and healthy behaviors. Health Psychology, 26, 121-125.

Harari, G. M., Müller, S. R., Aung, M. S., \& Rentfrow, P. J. (2017). Smartphone sensing methods for studying behavior in everyday life. Current Opinion in Behavioral Sciences, $18,83-90$.

Hennecke, M., Bleidorn, W., Denissen, J.J.A., \& Wood, D. (2014). A three-part framework for self-regulated personality development across adulthood. European Journal of Personality, 28, 289-299.

Henrich, J., Heine, S. J., \& Norenzayan, A. (2010). The weirdest people in the world? The Behavioral and Brain Sciences, 33, 61-83; discussion 83-135.

Hopwood, C. J. (2018). Interpersonal dynamics in personality and personality disorders. European Journal of Personality, 32, 499-524. 
Hopwood, C. J., Donnellan, M. B., Blonigen, D. M., Krueger, R. F., McGue, M., Iacono, W. G., \& Burt, S. A. (2011). Genetic and environmental influences on personality trait stability and growth during the transition to adulthood: A three-wave longitudinal study. Journal of Personality and Social Psychology, 100, 545-556.

Hopwood, C. J., Morey, L. C., Ansell, E. B., Grilo, C. M., Sanislow, C. A., McGlashan, T. H., ... \& Skodol, A. E. (2009). The convergent and discriminant validity of five-factor traits: Current and prospective social, work, and recreational dysfunction. Journal of Personality Disorders, 23, 466-476.

Hopwood, C. J., Thomas, K. M., Markon, K. E., Wright, A. G., \& Krueger, R. F. (2012). DSM-5 personality traits and DSM-IV personality disorders. Journal of Abnormal Psychology, $121,424-432$.

Hudson, N. W., \& Fraley, R. C. (2015). Volitional personality trait change: Can people choose to change their personality traits?. Journal of Personality and Social Psychology, 109, 490507.

Hudson, N. W., Roberts, B. W., \& Lodi-Smith, J. (2012). Personality trait development and social investment in work. Journal of Research in Personality, 46, 334-344.

Hutteman, R., Nestler, S., Wagner, J., Egloff, B., \& Back, M. D. (2015). Wherever I may roam: Processes of self-esteem development from adolescence to emerging adulthood in the context of international student exchange. Journal of Personality and Social Psychology, $108,767-783$.

Ilieva, I. (2015). Enhancement of healthy personality through psychiatric medication: The influence of SSRIs on neuroticism and extraversion. Neuroethics, 8, 127-137. 
Israel, A., Lüdtke, O., \& Wagner, J. (2019). The longitudinal association between personality and achievement in adolescence: Differential effects across all Big Five traits and four achievement indicators. Learning and Individual Differences, 72, 80-91. https://doi.org/10.1016/j.lindif.2019.03.001

Jackson, J. J., Thoemmes, F., Jonkmann, K., Lüdtke, O., \& Trautwein, U. (2012). Military training and personality trait development: Does the military make the man, or does the man make the military?. Psychological Science, 23, 270-277.

Javaras, K. N., Williams, M., \& Baskin-Sommers, A. R. (2019). Psychological interventions potentially useful for increasing conscientiousness. Personality Disorders, 10, 13-24.

John, O. P., \& Srivastava, S. (1999). The Big Five trait taxonomy: History, measurement, and theoretical perspectives. In L. A. Pervin \& O. P. John (Eds.), Handbook of personality: Theory and research (2nd ed., pp. 102-138). New York: Guilford.

Jokela, M., Bleidorn, W., Lamb, M.E., Gosling, S.D., Rentfrow, P.J. (2015). Geographically varying associations between personality and life satisfaction in the London metropolitan area. Proceedings of the National Academy of Sciences of the United States of America (PNAS), 112, 725-30.

Jokela, M., Hakulinen, C., Singh-Manoux, A., \& Kivimäki, M. (2014). Personality change associated with chronic diseases: pooled analysis of four prospective cohort studies. Psychological Medicine, 44, 2629-2640.

Judge, T. A., Bono, J. E., Ilies, R., \& Gerhardt, M. W. (2002). Personality and leadership: A qualitative and quantitative review. Journal of Applied Psychology, 87, 765-780. 
Kandler, C., Bleidorn, W., Riemann, R., Angleitner, A., \& Spinath, F. M. (2012). Life events as environmental states and genetic traits and the role of personality: A longitudinal twin study. Behavior Genetics, 42, 57-72.

Kandler, C., Bleidorn, W., Riemann, R., Spinath, F.M., Thiel, W., \& Angleitner, A. (2010). Sources of cumulative continuity in personality: A longitudinal multiple-rater twin study. Journal of Personality and Social Psychology, 98, 995-1008.

Kandler, C., Kornadt, A. E., Hagemeyer, B., \& Neyer, F. J. (2015). Patterns and sources of personality development in old age. Journal of Personality and Social Psychology, 109, 175.

Kandler, C., \& Ostendorf, F. (2016). Additive and synergetic contributions of neuroticism and life events to depression and anxiety in women. European Journal of Personality, 30, $390-405$.

Kandler, C., Waaktaar, T., Mõttus, R., Riemann, R., \& Torgersen, S. (in press). Unravelling the interplay between genetic and environmental contributions in the unfolding of personality differences from early adolescence to young adulthood. European Journal of Personality.

Kazdin, A. E. (1980). Behavior therapy: Evolution and expansion. In C. E. Thoresen (Ed.), The behavior therapist (pp. 71-78). Monterey, CA: Brooks/Cole.

Kendler, K. S., \& Baker, J. H. (2007). Genetic influences on measures of the environment: A systematic review. Psychological Medicine, 37, 615-626.

Kendler, K. S., \& Myers, J. (2010). The genetic and environmental relationship between major depression and the five-factor model of personality. Psychological Medicine, 40, 801806. 
Kern, M. L., \& Friedman, H. S. (2008). Do conscientious individuals live longer? A quantitative review. Health Psychology, 27, 505.

Klimstra, T. A., \& Denissen, J. J. A. (2017). A theoretical framework for the associations between identity and psychopathology. Developmental Psychology, 53, 2052-2065.

Kornadt, A. E., Hagemeyer, B., Neyer, F. J., \& Kandler, C. (2018). Sound body, sound mind? The interrelation between health change and personality change in old age. European Journal of Personality, 32, 30-45.

Kosinski, M., Matz, S. C., Gosling, S. D., Popov, V., \& Stillwell, D. (2015). Facebook as a research tool for the social sciences: Opportunities, challenges, ethical considerations, and practical guidelines. American Psychologist, 70, 543-556.

Kotov, R., Gamez, W., Schmidt, F., \& Watson, D. (2010). Linking "big” personality traits to anxiety, depressive, and substance use disorders: a meta-analysis. Psychological Bulletin, $136,768-821$.

Krasner, M.S., Epstein, R.M., Beckman, H., Suchman, A.L., Chapman, B., Mooney, C. J., Quill, T.E. (2009). Association of an educational program in mindful communication with burnout, empathy, and attitudes among primary care physicians. Journal of the American Medical Association, 302, 1284-1293.

Krueger, R. F., Hicks, B. M., Patrick, C. J., Carlson, S. R., Iacono, W. G., \& McGue, M. (2002). Etiologic connections among substance dependence, antisocial behavior and personality: Modeling the externalizing spectrum. Journal of Abnormal Psychology, 111, 411-424.

Le, K., Donnellan, M. B., \& Conger, R. (2014). Personality Development at Work: Workplace Conditions, Personality Changes, and the Corresponsive Principle. Journal of Personality, 82, 44-56. 
Lee, M. R., Ellingson, J. M., \& Sher, K. J. (2015). Integrating Social-Contextual and Intrapersonal Mechanisms of "Maturing Out": Joint Influences of Familial-Role Transitions and Personality Maturation on Problem-Drinking Reductions. Alcoholism: Clinical and Experimental Research, 39, 1775-1787.

Lehnart, J., Neyer, F. J., \& Eccles, J. (2010). Long-term effects of social investment: The case of partnering in young adulthood. Journal of Personality, 78, 639-669.

Lo, M.-T., Hinds, D. A., Tung, J. Y., Franz, C., Fan, C.-C., Wang, Y., . . Chen, C.-H. (2017). Genome-wide analyses for personality traits identify six genomic loci and show correlations with psychiatric disorders. Nature Genetics, 49, 152-156.

Lodi-Smith, J., \& Roberts, B.W. (2012). Concurrent and prospective relationships between social engagement and personality traits in older adulthood. Psychology and Aging, 27, 720727.

Lucas, R. E., \& Diener, E. (2015). Personality and subjective well-being: Current issues and controversies. In M. Mikulincer, P. R. Shaver, M. L. Cooper, \& R. J. Larsen (Eds.), APA handbook of personality and social psychology, Volume 4: Personality processes and individual differences (pp. 577-599). Washington, DC, US: American Psychological Association.

Lucas, R. E., \& Donnellan, M. B. (2011). Personality development across the life span: Longitudinal analyses with a national sample from Germany. Journal of Personality and Social Psychology, 101, 847-861.

Luciano, E. C., \& Orth, U. (2017). Transitions in romantic relationships and development of selfesteem. Journal of Personality and Social Psychology, 112, 307-328. 
Lüdtke, O., Roberts, B.W., Trautwein, U., \& Nagy, G. (2011). A random walk down university avenue: Life paths, life events, and personality trait change at the transition to university life. Journal of Personality and Social Psychology, 101, 620-637.

Luhmann, M., \& Eid, M. (2012). Studying reaction to repeated life events with discontinuous change models using HLM. In G. D. Garson (Ed.), Hierarchical linear modeling: Guide and applications (pp. 273-289). Thousand Oaks, CA: Sage

Luhmann, M., \& Eid, M. (2012). Studying reaction to repeated life events with discontinuous change models using HLM. Hierarchical linear modeling: Guide and applications, 273289.

Luhmann, M., Orth, U., Specht, J., Kandler, C., \& Lucas, R. E. (2014). Studying changes in life circumstances and personality: It's about time. European Journal of Personality, 28, 256266.

Luo, J., Derringer, J., Briley, D. A., \& Roberts, B. W. (2017). Genetic and Environmental Pathways Underlying Personality Traits and Perceived Stress: Concurrent and Longitudinal Twin Studies. European Journal of Personality, 31, 614-629.

Malouff, J. M., Thorsteinsson, E. B., \& Schutte, N. S. (2005). The Relationship Between the Five-Factor Model of Personality and Symptoms of Clinical Disorders: A Meta-Analysis. Journal of Psychopathology and Behavioral Assessment, 27, 101-114.

Malouff, J. M., Thorsteinsson, E. B., Schutte, N. S., Bhullar, N., \& Rooke, S. E. (2010). The five-factor model of personality and relationship satisfaction of intimate partners: A meta-analysis. Journal of Research in Personality, 44, 124-127. 
Markon, K.E., Krueger, R.F., \& Watson, D. (2005). Delineating the structure of normal and abnormal personality: An integrative hierarchical approach. Journal of Personality and Social Psychology, 88, 139-157.

McAdams, D. P., \& Olson, B. D. (2010). Personality development: Continuity and change over the life course. Annual Review of Psychology, 61, 517-542.

McCrae, R. R., \& Costa, P. (2008). The Five-Factor Theory of Personality. In O. P. John, R. W. Robins \& L. A. Pervin (Eds.), Handbook of personality: Theory and research (3rd ed.) (pp. 1-58). New York, NY, US: Guilford Press.

McCrae, R. R., Costa, P. T. J., Ostendorf, F., Angleitner, A., Hrebickova, M., Avia, M. D., .. . Smith, P. B. (2000). Nature over nurture: Temperament, personality, and life span development. Journal of Personality and Social Psychology, 78, 173-186.

Mihura, J. L., Meyer, G. J., Dumitrascu, N., \& Bombel, G. (2013). The validity of individual Rorschach variables: Systematic reviews and meta-analyses of the comprehensive system. Psychological Bulletin, 139, 548-605.

Miller, J. D., \& Lynam, D. (2001). Structural Models of Personality and Their Relation to Antisocial Behavior: A Meta-Analytic Review. Criminology, 39, 765-798.

Mõttus, R., Johnson, W., \& Deary, I. J. (2012). Personality traits in old age: Measurement and rank-order stability and some mean-level change. Psychology and Aging, 27, 243-249.

Mõttus, R., Kandler, C., Bleidorn, W., Riemann, R., \& McCrae, R. R. (2017). Personality traits below facets: The consensual validity, longitudinal stability, heritability, and utility of personality nuances. Journal of Personality and Social Psychology, 112, 474-490. 
Moffitt, T. E., Arseneault, L., Belsky, D., Dickson, N., Hancox, R. J., Harrington, H., ... Caspi, A. (2011). A gradient of childhood self-control predicts health, wealth, and public safety. Proceedings of the National Academy of Sciences, 108, 2693-2698.

Morey, L. C., \& Hopwood, C. J. (2013). Stability and change in personality disorders. Annual Review of Clinical Psychology, 9, 499-528.

Mu, W., Luo, J., Nickel, L., \& Roberts, B. W. (2016). Generality or specificity? Examining the relation between personality traits and mental health outcomes using a bivariate bi-factor latent change model. European Journal of Personality, 30, 467-483.

Mueller, S., Wagner, J., Drewelies, J., Duezel, S., Eibich, P., Specht, J., ... Gerstorf, D. (2016). Personality development in old age relates to physical health and cognitive performance: Evidence from the Berlin Aging Study II. Journal of Research in Personality, 65, 94108.

Mueller, S., Wagner, J., Smith, J., Voelkle, M. C., \& Gerstorf, D. (2018). The interplay of personality and functional health in old and very old age: Dynamic within-person interrelations across up to 13 years. Journal of Personality and Social Psychology, 115, $1127-1147$.

Mueller, S., Wagner, J., Wagner, G. G., Ram, N., \& Gerstorf, D. (in press). How far reaches the power of personality? Personality predictors of terminal decline in well-being. Journal of Personality and Social Psychology.

Noftle, E. E., \& Robins, R. W. (2007). Personality predictors of academic outcomes: big five correlates of GPA and SAT scores. Journal of Personality and Social Psychology, 93, 116. 
Olaru, G., Schroeders, U., Wilhelm, O., \& Ostendorf, F. (in press). 'Grandpa, do you like roller coasters?': Identifying age-appropriate personality indicators. European Journal of Personality. https://doi.org/10.1002/per.2185

Ormel, J., Jeronimus, B. F., Kotov, R., Riese, H., Bos, E. H., Hankin, B., ... \& Oldehinkel, A. J. (2013). Neuroticism and common mental disorders: meaning and utility of a complex relationship. Clinical Psychology Review, 33, 686-697.

Oltmanns, J. R., Jackson, J. J., \& Oltmanns, T. (in press). Personality change: Longitudinal selfother agreement and convergence with retrospective reports. Journal of Personality and Social Psychology.

Orth, U., Erol, R. Y., \& Luciano, E. C. (2018). Development of self-esteem from age 4 to 94 years: A meta-analysis of longitudinal studies. Psychological Bulletin, 144, 1045-1080.

Orth, U., \& Robins, R. W. (2014). The development of self-esteem. Current Directions in Psychological Science, 23, 381-387.

Orth, U., Robins, R. W., \& Widaman, K. F. (2012). Life-span development of self-esteem and its effects on important life outcomes. Journal of Personality and Social Psychology, 102, 1271.

Ozer, D. J., \& Benet-Martinez, V. (2006). Personality and the prediction of consequential outcomes. Annual Review of Psychology, 57, 401-421.

Paulhus, D. L., \& Vazire, S. (2007). The self-report method. In R. W. Robins, R. C. Fraley, \& R. F. Krueger (Eds.), Handbook of Research Methods in Personality Psychology (pp. 224 239). New York, NY, US: Guilford Press.

Penke, L., \& Jokela, M. (2016). The evolutionary genetics of personality revisited. Current Opinion in Psychology, 7, 104-109. 
Polderman, T. J. C., Benyamin, B., De Leeuw, C. A., Sullivan, P. F., Van Bochoven, A., .. . Posthuma, D. (2015). Meta-analysis of the heritability of human traits based on fifty years of twin studies. Nature Genetics, 47, 702-709.

Rauthmann, J. F., Sherman, R. A., \& Funder, D. C. (2015). Principles of situation research: Towards a better understanding of psychological situations. European Journal of Personality, 29, 363-381.

Roberts, B. W. (2009). Back to the Future: Personality and Assessment and Personality Development. Journal of Research in Personality, 43, 137-145.

Roberts, B. W. (2018). A revised sociogenomic model of personality traits. Journal of Personality, 86, 23-35.

Roberts, B. W., \& Bogg, T. (2004). A longitudinal study of the relationships between conscientiousness and the social-environmental factors and substance-use behaviors that influence health. Journal of Personality, 72, 325-354.

Roberts, B. W., Caspi, A., \& Moffitt, T. E. (2003). Work experiences and personality development in young adulthood. Journal of Personality and Social Psychology, 84, $582-593$

Roberts, B. W., \& Chapman, C. N. (2000). Change in Dispositional Well-Being and Its Relation to Role Quality: A 30-Year Longitudinal Study. Journal of Research in Personality, 34, $26-41$

Roberts, B. W., \& DelVecchio, W. F. (2000). The rank-order consistency of personality traits from childhood to old age: a quantitative review of longitudinal studies. Psychological Bulletin, 126, 3-25. 
Roberts, B. W., \& Jackson, J. J. (2008). Sociogenomic personality psychology. Journal of Personality, 76, 1523-1544.

Roberts, B. W., Kuncel, N. R., Shiner, R., Caspi, A., \& Goldberg, L. R. (2007). The power of personality: The comparative validity of personality traits, socioeconomic status, and cognitive ability for predicting important life outcomes. Perspectives on Psychological Science, 2, 313-345.

Roberts, B. W., Luo, J., Briley, D. A., Chow, P. I., Su, R., \& Hill, P. L. (2017). A systematic review of personality trait change through intervention. Psychological Bulletin, 143, 117141.

Roberts, B. W., Walton, K. \& Viechtbauer, W. (2006). Patterns of mean-level change in personality traits across the life course: A meta-analysis of longitudinal studies. Psychological Bulletin, 132, 1-25.

Roberts, B.W., \& Wood, D. (2006). Personality development in the context of the neosocioanalytic model of personality. In D. Mroczek \& T. Little (Eds.), Handbook of personality development (pp. 11-39). Mahwah, NJ: Erlbaum.

Roberts, B.W., Wood, D, \& Caspi, A. (2008). The development of personality traits in adulthood. In O.P. John, R.W. Robins, \& L. A. Pervin (Eds.), Handbook of Personality: Theory and Research (3rd edition, pp. 375-398). New York, NY: Guilford.

Roberts, B. W., Wood, D., \& Smith, J. L. (2005). Evaluating five factor theory and social investment perspectives on personality trait development. Journal of Research in Personality, 39, 166-184. 
Robins, R. W., Caspi, A., \& Moffitt, T. E. (2002). It's Not Just Who You're With, It's Who You Are: Personality and Relationship Experiences Across Multiple Relationships. Journal of Personality, 70, 925-964.

Sadler, P., Ethier, N., Gunn, G. R., Duong, D., \& Woody, E. (2009). Are we on the same wavelength? Interpersonal complementarity as shared cyclical patterns during interactions. Journal of Personality and Social Psychology, 97, 1005-1020.

Samuel, D. B., \& Widiger, T. A. (2008). A meta-analytic review of the relationships between the five-factor model and DSM-IV-TR personality disorders: A facet level analysis. Clinical Psychology Review, 28, 1326-1342.

Spengler, M., Brunner, M., Martin, R., \& Lüdtke, O. (2016). The Role of Personality in Predicting (Change in) Students' Academic Success Across Four Years of Secondary School. European Journal of Psychological Assessment, 32, 95-103.

Schwaba, T. \& Bleidorn, W. (2018). Individual differences in personality change across the adult lifespan. Journal of Personality, 86, 450-464.

Schwaba, T. \& Bleidorn, W. (2019). Personality development across the transition to retirement. Journal of Personality and Social Psychology, 116, 651-665.

Schwaba, T., Luhmann, M., Denissen, J.J.A., \& Bleidorn, W. (2018). Openness to experience and culture-openness transactions across the lifespan. Journal of Personality and Social Psychology, 15, 118-136.

Schwaba, T., Robins, R. W., Grijalva, E., \& Bleidorn, W. (in press). Does openness to experience matter in love and work? Evidence from a 24-year longitudinal study (in press). Journal of Personality. 
Scarr, S., \& McCartney, K. (1983). How people make their own environments: A theory of genotype $\rightarrow$ environment effects. Child Development, 54, 424-435.

Scollon, C. N., \& Diener, E. (2006). Love, work, and changes in extraversion and neuroticism over time. Journal of Personality and Social Psychology, 91, 1152-1165.

Selfhout, M. H. W., Burk, W. J., Denissen, J. J. A., Branje, S. J. T., van Aken, M. A. G., \& Meeus, W. H. J. (2010). Emerging late adolescent friendship networks and Big Five personality traits: A social network approach. Journal of Personality, 78, 509-538.

Sher, K. J., \& Trull, T. J. (1994). Personality and disinhibitory psychopathology: Alcoholism and antisocial personality disorder. Journal of Abnormal Psychology, 103, 92.

Sliwinski, M. J. (2008). Measurement-burst designs for social health research. Social and Personality Psychology Compass, 2, 245-261.

Specht, J., Bleidorn, W., Denissen, J.J.A., Hennecke, M., Hutteman, R., Kandler, C., Luhmann, M., Orth, U., Reitz, A., Zimmermann, J. (2014). What drives adult personality development? A comparison of theories and empirical evidence. European Journal of Personality, 28, 216-230.

Specht, J., Egloff, B., \& Schmukle, S.C. (2011). Stability and change of personality across the life course: The impact of age and major life events on mean-level and rank-order stability of the Big Five. Journal of Personality and Social Psychology, 101, 862-882.

Soto, C. J. (in press). How replicable are links between personality traits and consequential life outcomes? The Life Outcomes Of Personality Replication Project. Psychological Science. 
Srivastava, S., John, O. P., Gosling, S. D., \& Potter, J. (2003). Development of personality in early and middle adulthood: Set like plaster or persistent change?. Journal of Personality and Social Psychology, 84, 1041.

Stieger, M., Nißen, M., Rüegger, D., Kowatsch, T., Flückiger, C., \& Allemand, M. (2018). PEACH, a smartphone-and conversational agent-based coaching intervention for intentional personality change: study protocol of a randomized, wait-list controlled trial. BMC psychology, 6, 43.

Stopfer, J. M., Egloff, B., Nestler, S., \& Back, M. D. (2013). Being popular in online social networks: How agentic, communal, and creativity traits relate to judgments of status and liking. Journal of Research in Personality, 47, 592-598.

Sullivan, P. F. (2010). The psychiatric GWAS consortium: big science comes to psychiatry. Neuron, 68, 182-186.

Takahashi, Y., Edmonds, G. W., Jackson, J. J., \& Roberts, B. W. (2013). Longitudinal correlated changes in conscientiousness, preventative health-related behaviors, and self-perceived physical health. Journal of Personality, 81, 417-427.

Terracciano, A., Costa Jr, P. T., \& McCrae, R. R. (2006). Personality plasticity after age 30. Personality and Social Psychology Bulletin, 32, 999-1009.

Thoemmes, F. J., \& Kim, E. S. (2011). A systematic review of propensity score methods in the social sciences. Multivariate Behavioral Research, 46, 90-118.

Trull, T. J., \& Ebner-Priemer, U. (2013). Ambulatory assessment. Annual Review of Clinical Psychology, 9, 151-176.

Turkheimer, E. (2000). Three laws of behavior genetics and what they mean. Current Directions in Psychological Science, 9, 160-164. 
Turkheimer, E., \& Harden, K. P. (2014). Behavior genetic research methods: Testing quasicausal hypotheses using multivariate twin data. In H. T. Reis, \& C. M. Judd (Eds.), Handbook of research methods in social and personality psychology (2nd ed., pp. 159187). New York, NY: Cambridge University Press.

van Scheppingen, M. A., Denissen, J. J., \& Bleidorn, W. (2018). Stability and change in selfcontrol during the transition to parenthood. European Journal of Personality, 32, 690704.

van Scheppingen, M. A., Denissen, J. J. A., Chung, J. M., Tambs, K., \& Bleidorn, W. (2018). Self-esteem and relationship satisfaction during the transition to motherhood. Journal of Personality and Social Psychology, 114, 973-991.

van Scheppingen, M. A., Jackson, J. J., Specht, J., Hutteman, R., Denissen, J. J. A., \& Bleidorn, W. (2016). Personality development during the transition to parenthood: A test of social investment theory. Social Psychological and Personality Science, 7, 452-462

van den Berg, S. M., de Moor, M. H., Verweij, K. J., Krueger, R. F., Luciano, M., Vasquez, A. A., ... \& Hansell, N. K. (2016). Meta-analysis of genome-wide association studies for extraversion: Findings from the genetics of personality consortium. Behavior Genetics, $46,170-182$.

van Aken, M. A. G. van, Denissen, J. J. A., Branje, S. J. T., Dubas, J. S., \& Goossens, L. (2006). Midlife concerns and short-term personality change in middle adulthood. European Journal of Personality, 20, 497-513.

Vazire, S. (2006). Informant reports: A cheap, fast, and easy method for personality assessment. Journal of Research in Personality, 40, 472-481. 
Wagner, J., Becker, M., Lüdtke, O., \& Trautwein, U. (2015). The first partnership experience and personality development: A propensity score matching study in young adulthood. Social Psychological and Personality Science, 6, 455-463.

Wagner, J., Lüdtke, O., Roberts, B. W., \& Trautwein, U. (2014). Who Belongs to Me? Social Relationship and Personality Characteristics in the Transition to Young Adulthood. European Journal of Personality, 28, 586-603.

Wagner, J., Ram, N., Smith, J., \& Gerstorf, D. (2016). Personality trait development at the end of life: Antecedents and correlates of mean-level trajectories. Journal of Personality and Social Psychology, 111, 411.

Walton, K. E., \& Roberts, B. W. (2004). On the relationship between substance use and personality traits: Abstainers are not maladjusted. Journal of Research in Personality, 38, $515-535$.

Wille, B., Beyers, W., \& De Fruyt, F. (2012). A transactional approach to person-environment fit: Reciprocal relations between personality development and career role growth across young to middle adulthood. Journal of Vocational Behavior, 81, 307-321.

Wilson, R. S., Boyle, P. A., Yu, L., Segawa, E., Sytsma, J., \& Bennett, D. A. (2015). Conscientiousness, dementia related pathology, and trajectories of cognitive aging. Psychology and Aging, 30, 74.

Wille, B., \& De Fruyt, F. (2014). Vocations as a source of identity: Reciprocal relations between Big Five personality traits and RIASEC characteristics over 15 years. Journal of Applied Psychology, 99, 262-281. 
Wood, A. M., Brown, G. D. A., Maltby, J., \& Watkinson, P. (2012). How are personality judgments made? A cognitive model of reference group effects, personality scale responses, and behavioral reactions. Journal of Personality, 80, 1275-1311.

Wortman, J., Lucas, R. E., \& Donnellan, M. B. (2012). Stability and change in the Big Five personality domains: Evidence from a longitudinal study of Australians. Psychology and Aging, 27, 867-874.

Wright, A.G.C., Hopwood, C.J., Skodol, A.E., \& Morey, L.C. (2016). Longitudinal validation of general and specific structural features of personality pathology. Journal of Abnormal Psychology, 125, 1120-1134.

Wright, A.G.C., Hopwood, C.J., \& Zanarini, M.C. (2015). Associations between changes in normal personality traits and borderline personality disorder symptoms over 16 years. Personality Disorders: Theory, Research, and Treatment, 6, 1-11.

Wrzus, C. (2018). Processes of personality development: An update of the TESSERA framework. In J. Rauthmann (Ed.), The Handbook of Personality Dynamics and Processes (pp. nn): Elsevier.

Wrzus, C., \& Mehl, M. R. (2015). Lab and/or field? Measuring personality processes and their social consequences. European Journal of Personality, 29, 250-271.

Wrzus, C., \& Roberts, B. W. (2017). Processes of personality development in adulthood: The TESSERA framework. Personality and Social Psychology Review, 21, 253-277.

Zapko-Willmes, A., Riemann, R., \& Kandler, C. (2018). Unravelling quasi-causal environmental effects via phenotypic and genetically informed multi-rater models: The case of differential parenting and authoritarianism. European Journal of Personality, 32, 233253. 
Zimmermann, J., Woods, W. C., Ritter, S., Happel, M., Masuhr, O., Jaeger, U., . . Wright, A. G.C. (2019). Integrating structure and dynamics in personality assessment: First steps toward the development and validation of a Personality Dynamics Diary. Psychological Assessment, 31, 516-531. 
Figure 1. Four Pillars of Longitudinal Experience-Wide Association Studies.

\begin{tabular}{|c|c|c|c|}
\hline Timing & Sampling & Measurement & Experiments \\
\hline $\begin{array}{l}\text { Identify change trajectories } \\
\text { across states, traits, } \\
\text { environments, and individuals. }\end{array}$ & $\begin{array}{l}\text { Identify replicable principles of } \\
\text { personality change that } \\
\text { generalize across populations. }\end{array}$ & $\begin{array}{l}\text { Measure change in personality } \\
\text { traits, states, and the } \\
\text { environment across methods. }\end{array}$ & Strengthen causal inferences. \\
\hline $\begin{array}{l}\text { •Increase number of } \\
\text { personality assessments in } \\
\text { longitudinal designs } \\
\text { - Decrease intervals between } \\
\text { personality assessments } \\
\text { - Assess states and traits } \\
\text { alongside each other to } \\
\text { examine their interplay over } \\
\text { time } \\
\text { - Test hypotheses about the } \\
\text { frequency of assessments } \\
\text { necessary to capture } \\
\text { meaningful change across trait } \\
\text { domains } \\
\text { - Assess personality multiple } \\
\text { times before, during, and after } \\
\text { theoretically relevant } \\
\text { environmental changes or life } \\
\text { experiences } \\
\text { - Include measurement bursts, } \\
\text { especially during times when } \\
\text { change is expected }\end{array}$ & $\begin{array}{l}\text { - Examine personality change } \\
\text { across samples from different } \\
\text { cultures } \\
\text { - Increase the sample size of } \\
\text { longitudinal studies } \\
\text { - Use power analyses to } \\
\text { estimate required sample sizes } \\
\text { to detect small effects } \\
\text { - Increase the diversity of } \\
\text { samples } \\
\text { - Recruit samples that approach } \\
\text { representativeness of the } \\
\text { population studied } \\
\text { - Include relevant comparison } \\
\text { groups } \\
\text { - Use matching techniques to } \\
\text { compare personality change } \\
\text { across subsamples } \\
\text { - Include twin samples to } \\
\text { control for genetic and shared } \\
\text { environmental variance }\end{array}$ & $\begin{array}{l}\text { - Examine existing personality } \\
\text { measures with regard to their } \\
\text { sensitivity to change } \\
\text { - Develop new measures that } \\
\text { are sensitive to changes in } \\
\text { personality states and traits } \\
\text { - Use non-self-report measures } \\
\text { (e.g., informant reports, digital } \\
\text { footprints, mobile sensing, } \\
\text { narratives, behavioral tasks, } \\
\text { observational methods, or } \\
\text { biological markers) } \\
\text { - Develop psychologically } \\
\text { relevant measures of the } \\
\text { environment } \\
\text { - Validate measures across } \\
\text { groups (e.g., age, culture, } \\
\text { gender) } \\
\text { Develop state measures that } \\
\text { can distinguish motives, } \\
\text { cognitions, affects, and } \\
\text { behaviors within and across } \\
\text { trait domains } \\
\text { Develop measures that directly } \\
\text { assess processes theorized to } \\
\text { cause personality change }\end{array}$ & $\begin{array}{l}\text {-Complement observational } \\
\text { studies with experimental and } \\
\text { quasi-experimental designs } \\
\text { - Develop and validate treatment } \\
\text { protocols for personality } \\
\text { change interventions } \\
\text { - Use randomized controlled } \\
\text { trials (RCTs) and ABAB } \\
\text { designs to test personality } \\
\text { interventions } \\
\text { - Use instrumental-variable } \\
\text { regression and regression } \\
\text { discontinuity to analyze quasi- } \\
\text { experimental data }\end{array}$ \\
\hline
\end{tabular}

